Zh.V. Samokhvalova, V.N. Samokhvalov

\title{
MAGNETIC-PULSE PRESSING OF ELECTRICAL CONNECTIONS FOR STRANDED WIRES
}

Purpose. The research of the process peculiarities of magnetic- pulse fitting of electric stranded conductor joints, made of different materials, using couplings. Evaluation of loading optimal parameters, providing high operational reliability of electric connecting units. Methodology. In order to carry out simulation and research of the process of magnetic-pulse fitting of electric stranded conductor joints CRUG24 software package was used, which was developed to estimate impact interaction. Handling the problem was carried out numerically using finite differences. Metallographic study of collected cross-sectional cuts was performed with the use of optical microscope METAM ЛВ-71, equipped with digital-still camera, connected to the computer, which used image analysis system IMEGE Expert Pro3. The electrical tests of wire joints were carried out using the thermal bench from exposure to two factors: heating with rated current and expansion by operating load. Results. It was ascertained that magnetic-pulse pressing of electric joints was followed by partial self-purification and bedding component contacting surfaces of electric joints. Oxides and contaminating impurities were expelled into small localized zones between wires, between a wire and a coupling, which resulted in the contact of juvenile surfaces. Upon mutual deformation and displacement of metal wire surface capacity size and coupling tight mechanical contact was created, which provided minimal transient resistivity. The existence of residual compression stress provides the longstanding high-quality electric contact in joints. While using magnetic-pulse pressing of electric joints, due to high speed of deformation and impact of great inertial forces, deformation containment of connected components takes place in the zone of load action. The wires in contact with each other and with couplings generate faceting, but coupling sidewall hardly has any thinning. Filled density of cross-section is approximately $100 \%$. This fact provides a high degree of sealing capacity of joints, which to a wide extent prevents the oxidation of contacting surfaces and the rise of transient resistivity of electric joints in the operational process. As a result of processing of the results of thermal and electrical tests it was ascertained that pressed joint factors of defectiveness with all types of wires according to thermal impact and resistivity, are significantly lower than unity. Practical value. Magnetic-pulse pressing of unattended joints in electric stranded monometallic, bimetallic and composite conductors provides high operational reliability of connecting units and it may be used while mounting overhead system of railways, transmission lines and fitting connecting components of electrical transport electric circuits. References 9, figures 6.

Key words: magnetic-pulse assembly, connection of stranded wires, numerical simulation, electrical tests.

Розглянуто метод створення потужнострумових електричних з'єднань багатодротяних проводів при пресуванні затискачів імпульсним магнітним полем. Представлені результати чисельного моделювання та експериментальних досліджень процесу складання стикових з'єднань монометалевих, біметалевих та комбінованих проводів, в тому иислі при отриманні перехідних з'єднань алюміній-мідь. Викладено результати теплових та електричних випробувань з'єднань. Бібл. 9, рис. 6.

Ключові слова: магнітно-імпульсна збірка, з'сднання багатодротяних проводів, чисельне моделювання, електричні випробування.

Рассмотрен метод создания сильноточных электрических соединений многопроволочных проводов при прессовании зажимов импульсным магнитным полем. Представлены результаты численного моделирования и экспериментальных исследований процесса сборки стыковых соединений монометаллических, биметаллических и комбинированных проводов, в том числе при получении переходных соединений алюминий-медь. Изложены результаты тепловых и электрических испытаний соединений. Библ. 9, рис. 6.

Ключевые слова: магнитно-импульсная сборка, соединение многопроволочных проводов, численное моделирование, электрические испытания.

Problem definition. The analysis of the number of violations by types of technical devices and elements of the contact network of electrified railways of JSC Russian Railways for the period from 2003 to 2010 presented in the monograph [1] shows that in terms of the frequency of failures, wires and terminals occupy the first and the third place among all types of contact network devices (about $40 \%$ of all failures not caused by external causes). Heating in the terminals of electrical connectors, fatigue in the attachment points, weakening due to short-circuit are the main causes of failures. A large proportion of such damage is due to unacceptable temperature rises and the burnout of stranded wires in the spot-bolted connecting joints. To solve this problem, pressable terminals are used. The compressed terminals of the electrical connection joints are durable, lightweight, economical, require no maintenance, have non-degrading quality of the current-carrying connections, are resistant to corrosion and the effects of short-circuit currents.

Analysis of recent investigations and publications. Mechanical pressing of terminals is carried out using portable hydraulic presses using local indentation methods, as well as continuous or combined crimping using round or hexagonal dies. However, this results in an irregular crimping of the strands of the wire over its cross section. To improve the operational reliability of stranded copper wire connections with lugs 
in the electrical and aviation industry, the method of magnetic-pulse pressing of joints is used [2-4]. The connection is made during the high-speed crimping of the handpiece to the stranded wire. When a current pulse is passed through the inductor, transient magnetic field is excited, which induces eddy currents in the skin layer of the handpiece material. When the eddy current interacts with the inductor's magnetic field, forces arise that cause plastic deformation of the handpiece shell. This method can be applied in electric transport and in power supply systems of railways for butt joining of copper, aluminum, bimetallic and combined wires or press-on of handpieces.

Unlike mechanical pressing of terminals, when pulsed magnetic field is applied, the cylindrical part of the connecting sleeve or handpiece is deformed uniformly around the circumference, ensuring its electrical contact over all the conductors of the external strand of the wire. As a result of the high speed of the impact of the connected elements, as well as surface heating of the connectors with eddy currents and their subsequent cooling, additional compressive stresses arise that improve the quality of the connection of the sleeve and the stranded wire.

The goal of the work is investigation of the peculiarities of the process of formation of butt joints of stranded wires of various materials, including heterogeneous, determination of optimal parameters of magnetic-pulse loading, ensuring high operational reliability of electrical connecting joints.

Experimental investigations of stranded wire connections. During magnetic-pulse pressing, the parameters of the stranded wire connections are determined both by the initial dimensions of the connecting sleeve and the space-time characteristics of the magnetic field pressure pulse during the formation of the joint. The working tool that determines the plot of pressure in a magnetic-pulse assembly is an inductor. The experiments used multi-turn inductors with interchangeable magnetic field concentrators [5]. The working hole in the magnetic field concentrators was made for the sleeves with diameter of 16 to $28 \mathrm{~mm}$, which allowed to cover the entire size of the selected stranded wires. The width of the working area of the concentrator varied from 6 to $15 \mathrm{~mm}$. This made it possible to change the zone of action of the pulsed pressure of the magnetic field, as well as to additionally vary the value of the specific energy of the charge of the magnetic-pulse installation when receiving the connections of the wires. Variable parameters were the length and wall thickness of the connecting sleeve. The diameter of the sleeve and the minimum thickness of its wall in this case were set from the following conditions: the cross-sectional area of the sleeve is not less than the cross-sectional area of the wire; sleeve strength is not lower than the breaking strength of the wire.

An experimental study of the process of assembling the connection of wires was carried out on the magneticpulse installation МИУ-30 (manufactured by the Kharkiv Polytechnic Institute). The own inductance of the installation is $L=0.004 \mu \mathrm{H}$, the capacitance of capacitor batteries is $C=168 \mu \mathrm{F}$, the maximum charge voltage of capacitors is $U=19 \mathrm{kV}$, the maximum charge energy is $W=30.3 \mathrm{~kJ}$.

Metallographic studies of the cross-sections of the stranded wire connections obtained on the Gripo IV grinding and polishing machine were carried out using METAM ЛВ-71 optical microscope equipped with a digital camera connected to a computer using the IMEGE Expert Pro3 image analysis system. Studies of the macrosections of the joints obtained have shown that during magnetic-pulse pressing, due to high-speed collisions, the inner surface of the connecting sleeve (handpiece) is strongly deformed. This leads to an increase in the contact area of the sleeve and the wire in the joint compared with compression by hydraulic presses and, consequently, a decrease in the transient electrical resistance.

The cross-sections of the wire connections, obtained at the optimum value of the specific energy, showed that the wire has a contact across the entire wire surface (Fig. 1).

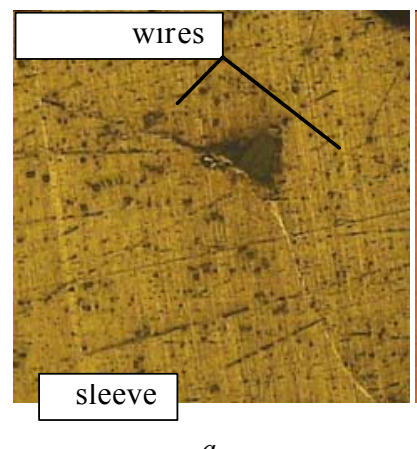

$a$

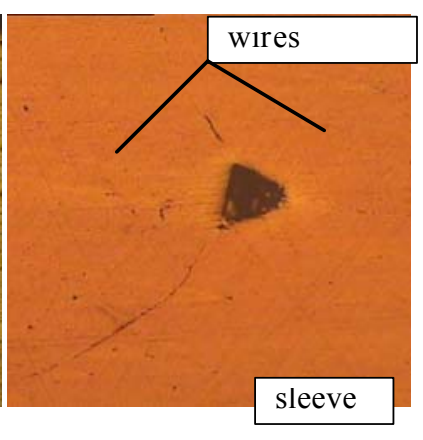

b
Fig. 1. View of contact of wires and the connecting sleeve at magnetic-pulse pressing of the joint:

a) aluminum wire and aluminum sleeve; b) copper wire and copper sleeve

Oxides and dirt are forced into small local areas between the wires, wires and the sleeve, contact of juvenile surfaces occurs.

The state of the boundaries between the individual wires, as well as between the wires and the sleeve in the joint depends mainly on the specific energy of the charge of the magnetic-pulse installation and the initial gap between the outer layer of wires and the inner surface of the connecting sleeve, determining the speed of the collision of the sleeve with the wire.

Upon receipt of the transitional joints of aluminum and copper stranded wires, the principal differences in the process of forming the joint of copper wire M-120 with an A0 aluminum sleeve and aluminum A-185 wire with an M1 copper sleeve were revealed. In the first case, the contact area of the sleeve with the external strand of the wire is much larger than in the joint of the aluminum wire A-185 with the copper sleeve. This is due to the «leakage» of the material of the soft aluminum sleeve between the copper wires, due to the effect of high-speed 
collision. In the second case, a more durable copper sleeve strongly crumples aluminum wires, but in both cases a high degree of tightness of the joint is ensured (Fig. 2).

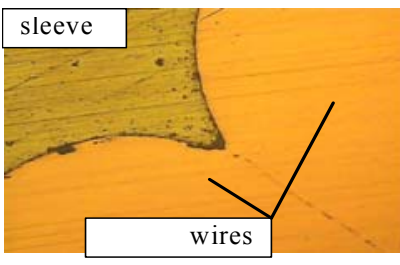

$a$

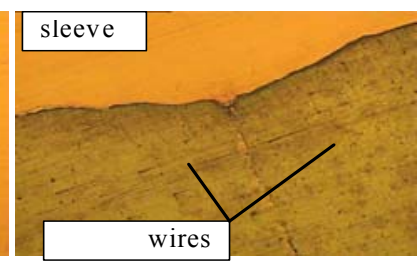

$b$
Fig. 2. Copper-aluminum transitional joint: a) copper wire and aluminum sleeve, b) aluminum wire and copper sleeve

Numerical simulation of the process of magneticpulse pressing of joints. To study the basic laws of the process of obtaining electrical joints by pulsed magnetic field, representatives of the main types of stranded wires of the power supply systems of railways and power lines were taken. This is supporting copper cable M-120 and aluminum auxiliary wire A-185; steel-copper bimetallic wire ПБСМ-95 (supporting cable of chain hangers, electric traction connectors, jumpers of choke transformers, etc.) and steel-aluminum combined wire AC-50/8 (suspension on overhead power lines). Materials of connecting sleeves are copper M1 and aluminum A0.

For the numerical simulation and study of the magnetic-pulse assembly of stranded wires joints using connecting sleeves, the software package CRUG24 was used developed for calculating shock interactions [6]. According to the method similar to $[3,4]$, the problem of deforming a system of cylindrical bodies enclosed in a circular shell (connecting sleeve or handpiece) was considered in 2D formulation. A pulsed magnetic field inductor is located around the shell. The connection is carried out in the process of high-speed crimping of the tubular connector or the handpiece to the stranded wire with the pressure of the pulsed magnetic field. The solution of this problem was carried out numerically using the finite difference method. The visual display of the process made it possible to control the calculation, to evaluate the parameters and features of the interaction of the sleeve and the wires.

For each element of the developed computational model, its individual physic-mechanical properties were specified. For example, in the numerical simulation of the magnetic-pulse assembly of the ПБСМ-95 steel-copper wires joint, inside each wire, the grid areas of the steel core and its copper shell were separated. In the numerical simulation of the assembly process of the steel-aluminum wires AC-50/8 with pressure of the pulsed magnetic field, various characteristics of the material of the central steel wire and its outer aluminum wires were specified.

In numerical modelling, the features of the formation of joints were studied:

a) «copper-copper» - connection of the M-120 or ПБСМ-95 wire with the copper connecting sleeve (or handpiece); b) «aluminum-aluminum» - connection of the wire A-185 or AC-50/8 with the aluminum connecting sleeve;

c) «copper-aluminum»transitional joints - M-120 wire with aluminum sleeve, A-185 wire with copper sleeve.

In the numerical simulation of the assembly processes, as in the experimental studies, the energy of the charge of the magnetic-pulse installation and the wall thickness of the connecting sleeve were varied. The process of assembling the connection of wires was modeled using the МИУ-30 magnetic-pulse installation used in the calculations with parameters, which was used during the full-scale experiments.

When conducting numerical simulation of the processes of a magnetic-pulse assembly, the coefficient of filling of the section $K_{z}$ in the terminal was calculated, which indirectly determines the mechanical strength of the joint and the transient electrical resistance [3]:

$$
K_{z}=4 F / \pi d^{2},
$$

where $F$ is the total cross-sectional area of the sleeve and wire, $d$ is the outer diameter of the sleeve after assembly of the joint.

The criterion for the efficiency of the assembly process was chosen to be the minimum specific energy of the charge of the magnetic-pulse installation, necessary to achieve complete compaction of the wires in the joint $\left(K_{\mathrm{z}} \approx 1\right)$. The specific energy $W_{u}$ on the assembly of the wire joint was determined as the ratio of the charge energy of the magnetic-pulse installation $W$ to the volume of the deformed material in the joint:

$$
W_{u}=W /(F / l), \mathrm{J} / \mathrm{mm}^{3},
$$

where $l$ is the width of the working zone of the inductor (magnetic field concentrator), which determines the length of the crimping zone in the resulting joint.

As shown by the results of numerical simulation of the assembly of joints by pressure of the pulsed magnetic field and the results of metallographic studies of the joints obtained, the interaction of the sleeve with the monometallic wires of the M-120 and A-185 wires at optimum specific energy leads to a uniform deformation of the majority of the wires, their complete compaction and cutting (Fig. 3).

In the steel-aluminum combined wire $\mathrm{AC}-50 / 8$, its central steel wire is deformed slightly, the compaction of the joint is ensured by the deformation of aluminum wires.

In joints of steel-copper wires ПБСМ-95 using copper sleeves, there is a slight deformation of the steel core of the wires in the bimetallic wires, and their copper shell is deformed to a much greater degree, which coincides with the results of numerical simulation. Due to this, there is a fairly strong leakage of the material of the copper sleeve in the cavity between the wires, which further increases the contact area of the sleeve and wire in the joint (Fig. 4).

In case of insufficient specific energy, the wires are not fully compacted in the joint $\left(K_{z}<1\right)$, which does not provide the desired quality of the joint. With a 
rational mode of magnetic-pulse loading, the deformation of the wires and the final compression of the entire wire occur at the stage of maximum acceleration of the connecting sleeve (handpiece), which ensures the closing of all the wires and filling the entire cross-section of the joint $\left(K_{z} \approx 1\right)$.
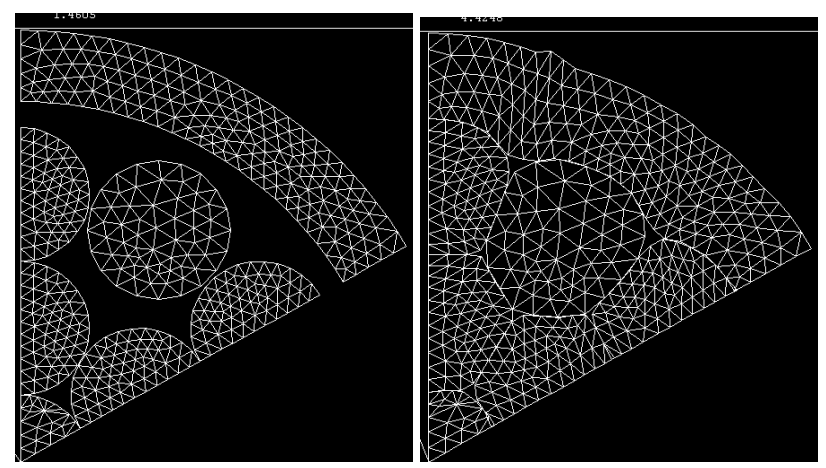

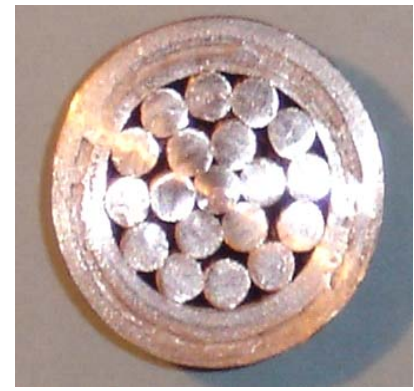

$a$

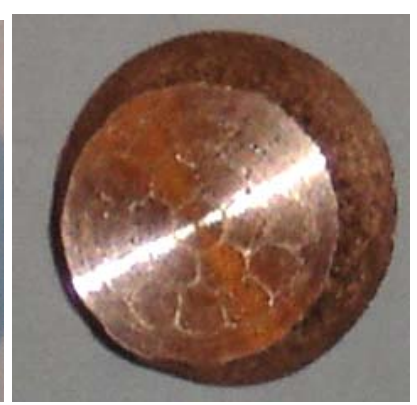

$b$
Fig. 3. View of joint of the wire M-120 and the copper sleeve in the numerical simulation and full-scale experiment: a) before crimping, $b$ ) after assembling

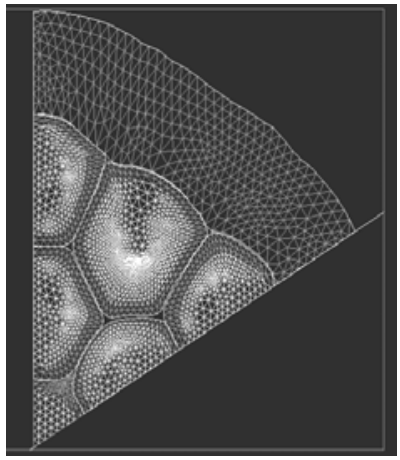

$a$

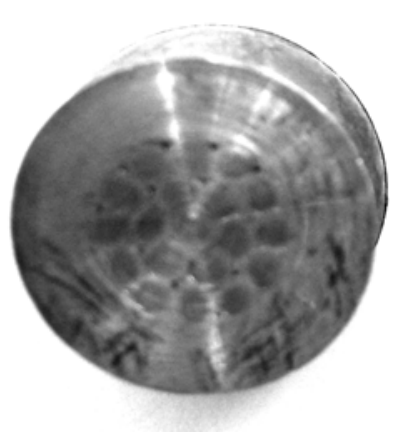

b
Fig. 4. View in cross section of the wire ПБСМ-95 and copper connecting sleeve in magnetic-pulse assembly:

a) numerical simulation, $b$ ) experiment

This is achieved if the maximum of the first halfwave of the pressure of the pulsed magnetic field coincides with the maximum of the speed of deformation of the connecting sleeve. As shown by the simulation of the process, the speed of deformation of the connecting sleeve, in the process of assembling (crimping) the joint, reaches $150 \ldots 200 \mathrm{~m} / \mathrm{s}$, and the process time is $18 \ldots 25 \mu \mathrm{s}$, depending on the material and wall thickness of the connecting element (sleeve, handpiece). With an excess of the specific energy of the charge of the magnetic-pulse installation, the maximum deformation speed of the connecting sleeve does not coincide with the maximum of the first half-wave of pressure of the pulsed magnetic field. There is an overrun of the energy of the charge of the magnetic-pulse installation and an irrational force effect on the resulting joint which does not increase its quality.

As a result of processing the calculation results, we obtained the dependencies of the minimum calculated specific energy of the charge of the magnetic-pulse installation, at which $K_{z} \approx 1$ is reached, using sleeves with different wall thicknesses having a tensile strength not lower than the wire strength (Fig. 5).

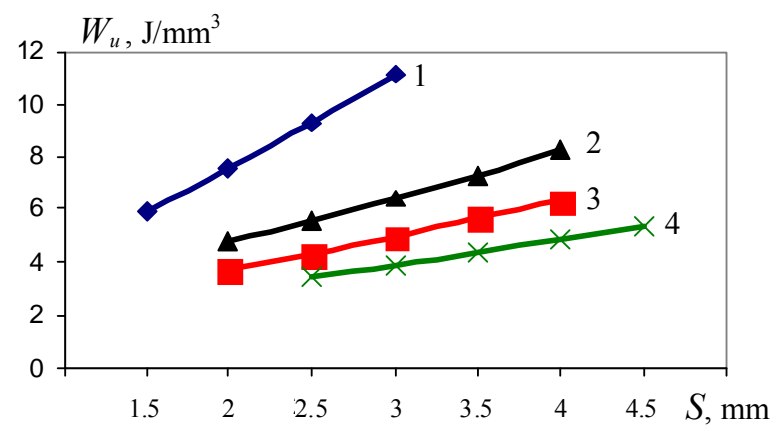

Fig. 5. Dependence of the minimum specific energy of the assembly of the joint of wires on the thickness of the connecting sleeve.

Wire: 1) AC 50/8, 2) ПБСМ-95, 3) М-120, 4) A-185

Electrical testing of the obtained wire joints. Electrical tests were conducted indoors using a thermal bench. Quality control of the joints of stranded wires produced by the pressure of the pulsed magnetic field was carried out in accordance with GOST 12393-77 [7]. The properties of the stranded wire joints were evaluated according to standard indicators, as well as under the influence of two factors: heating with rated current and tension by the working load. For complex tests, a special device for mechanical loading of joints was manufactured. The device is equipped with interchangeable collet clamps for gripping wires of different diameters installed in dielectric (textolite) plates (Fig. 6).

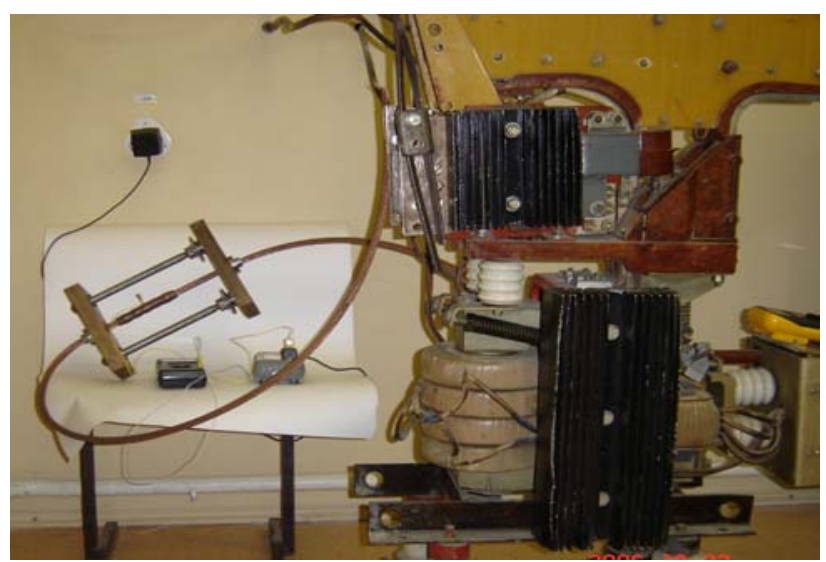

Fig. 6. Thermal bench and device for mechanical loading of butt joints of wires

Textolite plates are interconnected by two racks, one end of which is rigidly connected to the first plate and the other end enters the hole of the second plate. The distance 
between the plates was changed due to the rotation of the nuts resting through a pair of cup springs on the second plate. The tensile force of the wire joint was controlled by the compression of calibrated cup springs. The cup springs made it possible to keep the load force of the joint almost unchanged under axial thermal deformation of the wires and the connecting sleeve during thermal testing.

The quality of the electrical connection was determined by the defectiveness coefficients of the electrical contact by electrical resistance $-\mathrm{KR}$ and by overheating by nominal rated current $-K_{\theta}$ :

$$
K_{R}=\Delta U_{C} / \Delta U_{P}, \quad K_{\theta}=\Delta \theta_{C} / \Delta \theta_{P},
$$

where $\Delta U_{\mathrm{C}}$ and $\Delta U_{P}$ are, respectively, the voltage drop at the joint and on the whole wire part of the same length, $\mathrm{mV} ; \Delta \theta_{C}$ and $\Delta \theta_{P}$ are, respectively, the temperature rise of the terminal and the connected wire outside the terminal above the ambient temperature when the same current flows through them, ${ }^{\circ} \mathrm{C}$.

The current value for determining the defectiveness coefficients was set taking into account the permissible continuous current value for each brand of connecting wires, established by the regulatory and technical documentation [8]: 400, 500 and $600 \mathrm{~A}$, and was maintained constant with an error of no more than $3 \%$ during the test (controlled by a multimeter Masteh MY-62). The overheating temperature of the joint (middle of the connecting sleeve) and the wire (at a distance of 1 $\mathrm{m}$ from the sleeve) was measured using thermocouples and an APRA 109 digital multimeter (class 0.1). The voltage drop on the wire and in the joint was measured at each selected current value by a digital multimeter Masteh M890G (class 0.1). The defectiveness coefficient for resistance was determined as the arithmetic average of three values obtained at three current values.

Defectiveness coefficients of the joints were determined for the joints of the M-120 and ПБСМ-95 wires using copper sleeves; the A-185 wires joints using aluminum sleeves. For transitional joints of the wire M120 and the wire A-185 aluminum and copper sleeves were used, respectively.

It has been established that the overheating temperature of the joints obtained is substantially lower than the overheating temperature of the wires themselves outside the joint. The resulting defectiveness coefficients of electrical contact changed from $K_{R}=0.56$ and $K_{\theta}=0.66$ for joints of the ПБСМ-95 wires to $K_{R}=0.74$ and $K_{\theta}=0.88$ for the transitional butt joint of the wires M120 and A185, which is lower the values established for the joints of the stranded wires of the contact network of electrified railways, made by the method of crimping [7].

To improve the quality of the connection of stranded wires produced by the pressure of pulsed magnetic field, a device [9] has been developed, which, in the process of magnetic-pulse pressing of terminals, pre-compresses the wires and creates tensile stresses in them. This allows, after assembling the joint, to create additional residual compressive stresses in the resulting joint, providing a high breaking force of the sleeve and minimal transient electrical resistance, as well as high density in the joint, minimizing oxidation of the contact surfaces.
Conclusions. As a result of investigations the following was found:

1. Magnetic-pulse pressing is accompanied by partial self-cleaning and grinding in the contacting surfaces of the elements of the electrical connection in the process of forming the joint. During high-speed collision and joint deformation of the bodies being joined, large shear stresses and contact pressures occur. Oxides and dirt are forced out into small local zones between the wires, wires and the sleeve, which leads to the contact of juvenile surfaces. With the mutual deformation and displacement of the surface volumes of the metals of the wires and the connecting element, a close physical contact is created, which ensures the minimum transient electrical resistance. This ensures high quality electrical contact in the joint.

2. At the magnetic-pulse assembly of electrical connections, due to the high speed of deformations and the action of large inertial forces, the deformations are localized in the load action zone. The wires at the places of contact with each other and with the sleeve get cut, and the wall of the sleeve has practically no thinning. Therefore, in contrast to the assembly of joints by hydraulic presses, with magnetic-pulse crimping there is practically no weakening of the wire cross section. In the case of magnetic-pulse assembly, the wires in the joint are compacted, the filling density of the cross section approaches $100 \%$, which ensures a high degree of tightness of the joint. This largely prevents oxidation of the contacting surfaces and an increase in the transient resistance of the electrical connection during operation.

3. As a result of processing the results of thermal and electrical tests, it was established that the defectiveness coefficients of the press joint of all types of wires for heating and electrical resistance are significantly lower than one, which ensures high operational reliability of the electrical connecting joints of the stranded wires of the contact network, electric transport and transmission lines obtained by magnetic-pulse pressing.

\section{REFERENCES}

1. Galkin A.S., Mitrofanov A.N., Mitrofanov S.A. Matematicheskoe modelirovanie i informatsionnye tekhnologii $v$ zadachakh diagnostiki kontaktnoi seti elektrifitsirovannykh zheleznykh dorog [Mathematical modeling and information technologies in diagnostics of the contact network of electrified railways]. Ekaterinburg, Ural State University of Railway Transport Publ., 2012. 226 p. (Rus).

2. Dmitriev V.V., Lifshits Iu.Ia., Rozin V.I. Magnetic-pulse processing of electrical engineering parts. Forging and Stamping Production, 1984, no.7, pp. 8-9. (Rus).

3. Kurlaev N.V., Gulidov A.I, Iudaev V.B. Numerical simulation of the process of assembly of the tips with electric clamps with the pressure of a pulsed magnetic field. Forging and Stamping Production. Material Working by Pressure, 2001, no.8, pp. 38-42. (Rus).

4. Kurlayev N., Gulidov A., Ryngach N., Mishukov A. Computer simulation of aircraft wires tips compression by pulse magnetic field. 5th Korea-Russia International Symposium on Science and Technology. Proceedings. KORUS 2001, vol., pp. 36-39 (Cat. No.01EX478). doi: 10.1109/korus.2001.975047.

5. Belyj I.V., Fertik S.M., Khimenko L.T. Spravochnik po magnitno-impulsnoj obrabotke metallov [Directory of magnetic-pulse treatment of metals]. Kharkiv, Vishcha shkola Publ., 1977, 189 p. (Rus). 
6. Fomin V.M., Gulidov A.I., Sapozhnikov G.A. Vysokoskorostnoe vzaimodeistvie tel [High-speed interaction of bodies]. Novosibirsk, Siberian Branch Russian Academy of Sciences Publ., 1999. 600 p. (Rus).

7. GOST 12393-77. Armatura kontaktnoi seti dlia elektrifitsirovannykh zheleznykh dorog. Obshchie tekhnicheskie usloviia [State Standard 12393-77. Armature of the contact network for electrified railways. General specifications] Moscow, Standartinform Publ., 2004. 26 p. (Rus).

8. Pravila ustroistva i tekhnicheskoi ekspluatatsii kontaktnoi seti elektrifitsirovannykh zheleznykh dorog (TsE-868) [Rules of the device and technical operation of the contact network of electrified railways]. Department of Electrification and Electricity of the Ministry of Railways of the Russian Federation. Moscow, Transizdat Publ., 2002. 184 p. (Rus).

9. Samokhvalov V.N., Grigor'ev V.L., Samokhvalova Zh.V. Ustroistvo dlia soedineniia mnogoprovolochnykh provodov [Device for connecting stranded wires]. Patent Russian Federation, no. 53819, 2006. (Rus).

Received 20.09.2018

How to cite this article:

Samokhvalova Zh.V., Samokhvalov V.N. Magnetic-pulse pressing of electrical connections for stranded wires. Electrical engineering \& electromechanics, 2019, no.1, pp. 51-56. doi: 10.20998/2074-272X.2019.1.09.
Zh.V. Samokhvalova ${ }^{1}$, Candidate of Technical Science, Associate Professor,

V.N. Samokhvalov ${ }^{2}$, Doctor of Technical Science, Professor,

${ }^{1}$ Samara State Transport University,

2V, Svobody Str., Samara, 443066, Russia,

phone +7 9276568357 ,

e-mail: zhanna_sam@mail.ru

${ }^{2}$ Samara National Research University,

34, Moskovskoye shosse, Samara, 443086, Russia,

phone +7927 6544210,

e-mail: vn_samokhvalov@mail.ru 